PLAYING LIKE A TEAM IN TEAMS Prestridge and Cox analysed the student discussions on the Teams chat forum patterns. They studied the 281 posts patterns. They studied the 281 posts individual posts, and the interactions between them, from Module 2. The researchers identified three themes of student engagement from Module 1: background participation, which included posts about the course content or agreeing with another student's post; engaging with content, which involved discussing and reflecting on the course content; and generating content, which involved proactively locating digital tools for the assessment tasks.

From the Module 2 posts and their interactions, Prestridge and Cox identified six categones of engagen onts of task, reprompled lower supericial, and complexity, and involved students simply liking/agreeing with others, using emoiis and completing assigned tasks; while respond, expand, and create, represe greater cognitive complexity, such as engaging in active discussions about the course content. Unlike lurk, superficial and task, where students essentially engaged for themselves (as they might in teachercentred methods), students in respond. expand, and create categories engaged with each other to create a community of inquiry in which they acted to extend each other's thinking. in the researchers' words, they 'played like a team in Teams'.

\section{A TYPOLOGY OF}

\section{ONLINE ENGAGEMENT}

The researchers then looked again to deternine he complexily and intensity they created a new typology of cognit social engagement, of four different learner profiles:

Bench Sitter - a student who does not post frequently or with high complexity liking or agreeing but not contributing new information.

Hustler- students who frequently acknowledge other's posts but don't engage in meaningful, more complex, exchanges.

Striker - students who may not engage often complex and thought-provoking,

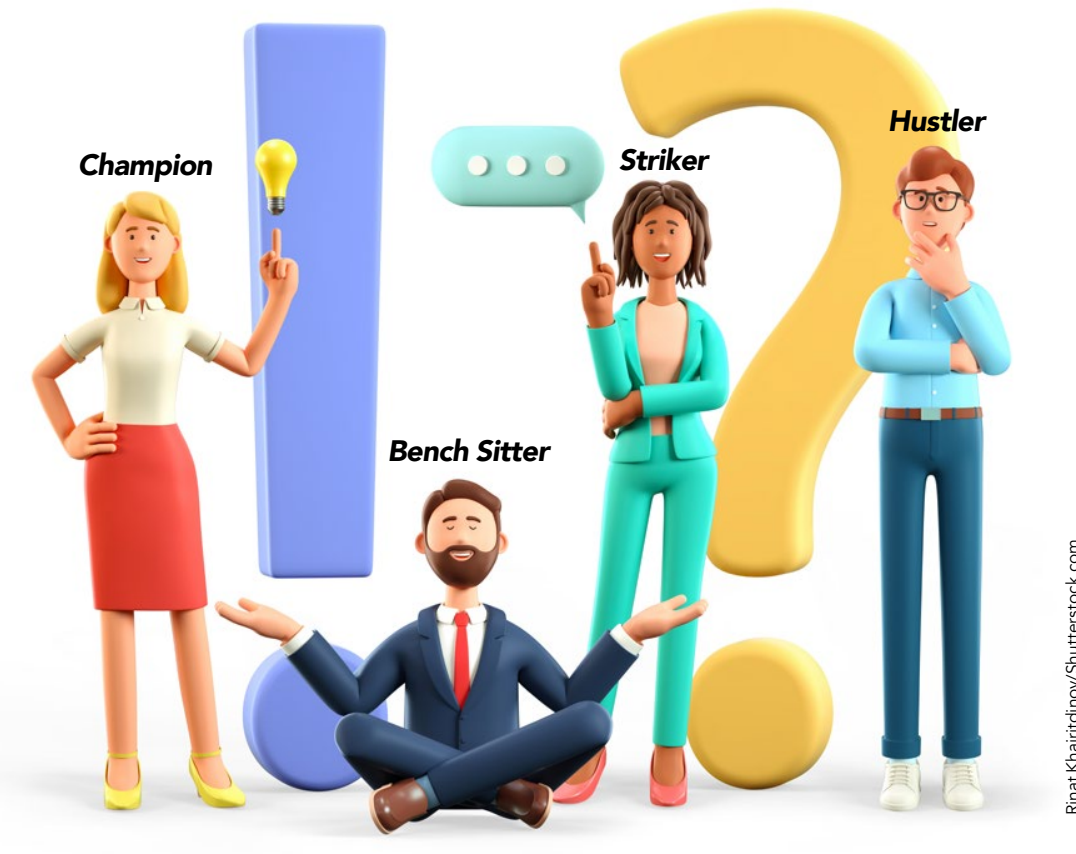

with contributions that are new or expand on existing topics.

Champion - students who explored the course content more deeply throug frequent and complex posts, sharing their own ideas, asking questions and supporting their peers. Champions championed others within the chat stream, expanding upon ideas.

Despite the limited cohort studied, Prestridge and Cox believe these studen courses and evaluating different teaching interventions, enabling teachers to understand the differences between the highly visible hustler student and the less visible but more complex contributions of the striker, for example, or understanding how to enable a bench sitter to become

Some students engaged with each other to create a community of inquiry in which they acted to extend each other's thinking.

The researchers highlight that the student profiles they studies' find not reflect previous small percentage of students demonstrate complex cognition, as they found that $40 \%$ of the students - who made up the champions and strikers - demonstrated complex engagement. Contrary to the idea that students' capabilities determine the complexity of their engagements, this more nuanced understanding suggests that, when the appropriate collaborative space is provided, students make a choice about whether and how to engage. As in all environments, students may choose to engage for a number of reasons. These profiles can provide students with give ho how they are behaving and give teachers the language to talk about students themselves. a champion (though they emphasise the need for further research to understand different engagement types in this way would improve their learning outcomes the nature of learning communities).

The researchers suggest that using further research could provide a better understanding of effective online course design and teaching methods, as well as understanding what student engagement.

Their findings could be particularly usefu for school and university teachers, to between students. Such information will continue to be important poststill need to engage in sudents learning opportunities. these profiles as a foundation for aspects of course design can influence facilitate effective online collaboration

\section{A Behind the Research Dr Sarah Prestridge \\ Alinthill \\ E: s.prestridge@griffith.edu.au T: $37355816 \quad$ W: experts.griffith.edu.au/9530-sarah-prestridge}

\section{Research Objectives}

How online environments can be used to improve the student learning experience.

\section{Detail}

\section{Address}

Digital Pedagogies

Griffith University

176 Messines Ridge

Mount Gravatt, Queensland, 4122 Australia

Bio

Sarah Prestridge is the 2020 Top Scholarly Researcher in Teaching in Teacher Education in Australia. Her passion for transforming learning through digital technologies has taken her from classroom teacher to university researcher. She has developed strong theoretical frameworks that conceptualise 'best practice' with digital learning and teaching, and theorised key principles of transformative Professional Development.

Collaborators

(co-author)

以上 Griffith Queensland, Australia

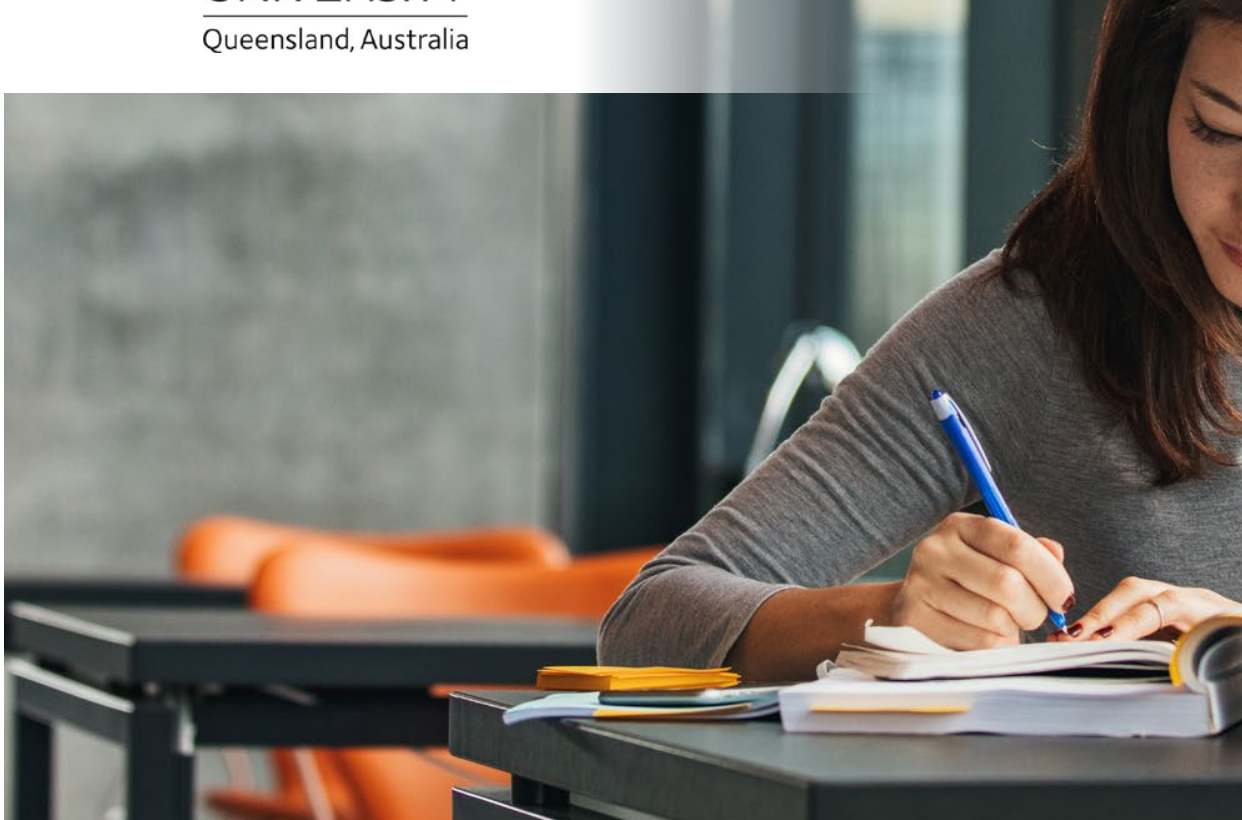

References

Prestridge S, Cox D, (2021) Play like a team in

teams: A typology of online cognitive-social learning engagenent. Active Leaming in Higher Education. do

Personal Response

How might we identify a relationship between learner profiles, online social learning behaviour, and academic outcomes?

II I think the issue here is more on the process which is as important as focusing on academic outcome. If we can improve the online learning process then we can improve
learner academic outcome. This research has highlighted that designing a community-oriented discussion forum leads to greater student cognitive-social learning agency. build students' metacognition by making them aware of the choices they are making and the learning actions
taking place.

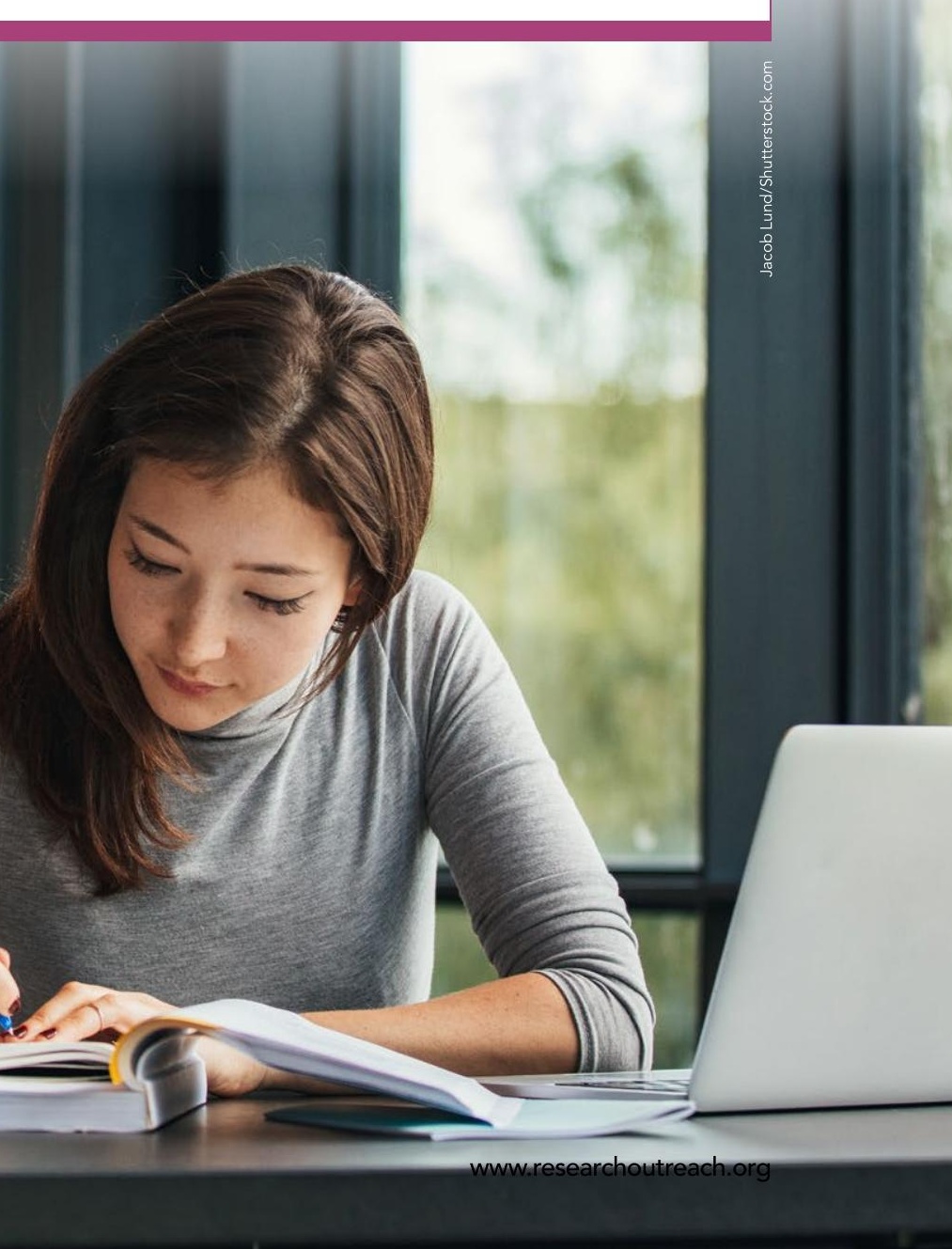

